\title{
Noninvasive Ventilation in Obese Patients After Acute Respiratory Failure: Big Questions Remain
}

Obesity is a global health epidemic, ${ }^{1}$ and obesity-hypoventilation syndrome is increasingly common; the prevalence of obesity-hypoventilation syndrome in patients attending sleep laboratories or admitted to hospitals is estimated to be $11-38 \%,,^{2-4}$ while estimates of the prevalence in the general population range from $0.3 \%$ to $0.4 \%^{5}$ In many countries, obesity-hypoventilation syndrome is the most common indication for domiciliary noninvasive ventilation (NIV). 6,7

The term obesity-hypoventilation syndrome is used to define individuals with obesity (body mass index [BMI] $>30 \mathrm{~kg} / \mathrm{m}^{2}$ ) and diurnal hypoventilation (daytime $\mathrm{P}_{\mathrm{aCO}_{2}}$ $>45 \mathrm{~mm} \mathrm{Hg}$ ) in the absence of any other cause of hypoventilation. ${ }^{8}$ Although not included in the definition, these individuals usually (but not always) have sleepdisordered breathing, consisting of rapid eye movement, sleep hypoventilation, obstructive sleep apnea (in 90\% of patients with obesity-hypoventilation syndrome ${ }^{9,10}$ ), or both. ${ }^{11}$

Most patients are diagnosed with obesity-hypoventilation syndrome because of an increase in daytime and/or sleep-related symptoms, but about one third are not diagnosed until an episode of acute respiratory failure. ${ }^{12-14} \mathrm{Of}$ all the complications related to obesity, the development of respiratory failure is probably the most significant because it is associated with a 4-fold increase in mortality if left untreated. ${ }^{3}$ Without treatment, individuals with obesity-hypoventilation syndrome are at risk of pulmonary hypertension, cor pulmonale, and acute respiratory failure. Compared with obese patients without daytime hypercapnia, individuals with obesity-hypoventilation syndrome have higher rates of hospital admission, increased use of intensive-care resources, worse health-related quality of life scores, and reduced functional capacity and physical activity levels. ${ }^{15,16}$

Although weight loss is the ideal treatment for obesityhypoventilation syndrome, ${ }^{17}$ in practice it is difficult to

The author has disclosed no conflicts of interest.

Correspondence: Alanna Hare MB MRCP MEd, Department of Ventilation and Sleep, Royal Brompton Hospital, Sydney Street, London SW3 6NP. E-mail: a.hare@rbht.nhs.uk.

DOI: $10.4187 /$ respcare.06020 achieve and maintain in this group. Bariatric surgery is also often not an alternative for this group because of the significant morbidity and mortality. ${ }^{18}$

Positive airway pressure (PAP) is effective in managing

See the Original Study on Page 28

both acute and chronic respiratory failure due to obesityhypoventilation syndrome. ${ }^{9,19-23}$ Despite this, there are no established guidelines for the use of NIV or CPAP in subjects with obesity-hypoventilation syndrome, and to date only a few randomized controlled trials have been published. Nevertheless, there is a strong physiologic rationale for the use of PAP in obesity-hypoventilation syndrome, and evidence supporting its use in this area is growing.

Although the mechanisms by which obesity-hypoventilation syndrome results in diurnal respiratory failure are not entirely understood, there appear to be 3 main mechanisms at play ${ }^{24}$ : abnormal respiratory mechanics, including respiratory muscle dysfunction; 25 central hypoventilation due to leptin resistance; ${ }^{26-29}$ and sleep-disordered breathing, both sleep hypoventilation and obstructive apneas. ${ }^{5,30}$ PAP, either in the form of CPAP or NIV, is able to influence all 3 of these areas, although the exact mechanism(s) by which these treatments are able to improve respiratory failure in obesity-hypoventilation syndrome are complex and remain to be fully explained.

In acute hypercapnic respiratory failure due to obesityhypoventilation syndrome, although no randomized clinical trial has been conducted to test the effectiveness of NIV for this indication, NIV is the preferred mode of ventilatory support, unless the patient is severely unwell or there is other organ dysfunction, in which case endotracheal intubation and mechanical ventilation in the ICU is mandatory. ${ }^{31} \mathrm{NIV}$ in this cohort results in improvements in $\mathrm{pH}$ and $\mathrm{P}_{\mathrm{aCO}},{ }^{9}, 20,22,32,33$ with lower mortality in patients treated with NIV compared with those who refused it (3\% mortality with NIV and $57 \%$ without $^{9}$ ). Lemyze and co-workers, ${ }^{31}$ in a study exploring the determinants of NIV success in acute respiratory failure in the morbidly obese, found that pneumonia and high symptom-severity scores at admission were associated with NIV failure in this group, while high $\mathrm{P}_{\mathrm{aCO}_{2}}$ and $\mathrm{HCO}_{3}$ levels at 
admission and idiopathic hypercapnic decompensation of obesity-hypoventilation syndrome were associated with successful NIV application.

The benefits of positive airway pressure (CPAP or NIV) in chronic respiratory failure due to obesity-hypoventilation syndrome have been demonstrated in randomized controlled trials. ${ }^{34,35}$ Both therapies result in significant reductions in daytime $\mathrm{P}_{\mathrm{aCO}}$ and bicarbonate, as well as improvements in apnea-hypopnea index, with restoration of sleep architecture and improvements in daytime sleepiness. ${ }^{34-37}$ Some health-related quality of life measures improve to a greater extent with NIV compared to CPAP. ${ }^{34}$

In the chronic setting, there are 3 distinct patterns of sleep-disordered breathing, which can be determined on the basis of respiratory sleep studies: isolated severe obstructive sleep apnea; isolated sleep hypoventilation; and combined obstructive sleep apnea and hypoventilation. Each of these merits a different management strategy.

In patients with a predominance of obstructive events during sleep, and high sleep time in apnea, in whom daytime $\mathrm{P}_{\mathrm{aCO}_{2}}$ is $<55 \mathrm{~mm} \mathrm{Hg}$, CPAP is clinically and costeffective $^{37}$ and has been shown to be equivalent to NIV, at least in the medium term, in newly diagnosed patients with both mild and severe obesity-hypoventilation syndrome. ${ }^{34,36,37}$ In those patients with persistent nocturnal hypoventilation on CPAP, or with a predominance of hypoventilation over obstructive events on initial sleep study, NIV is preferred, and should be established with the aim of normalizing daytime $\mathrm{P}_{\mathrm{aCO}}$. Following adequate treatment, demonstrated by normalization of daytime blood gas tensions, it may be possible to step these patients down to CPAP therapy.9,36,38 Importantly, clinical outcomes are closely related to adherence with therapy: an average use of $4 \mathrm{~h}$ per night is recommended in order to achieve a reduction in daytime $\mathrm{P}_{\mathrm{aCO}}$ levels, and it is this latter which is associated with improvements in health related quality of life measures and daytime sleepiness. ${ }^{34,36,37}$

In this edition of Respiratory CARE, Bry and co-work$\mathrm{ers}^{39}$ present data on the predictors of long-term NIV use in a cohort of obese subjects (mean BMI $42 \pm 11 \mathrm{~kg} / \mathrm{m}^{2}$ ) admitted to their respiratory ICU with acute hypercapnic respiratory failure. In this retrospective study, the authors identified 53 subjects over a 2-year period, in which $70 \%$ of subjects were presenting for the first time in respiratory failure; 8 subjects had previously been prescribed home NIV, but only one was using the device on a regular basis by the time of the study, while 9 subjects had previously been prescribed CPAP. Unfortunately, no previous sleep study data were presented, and it is not possible to determine whether these 17 subjects had sleep hypoventilation, sleep apnea, or a combination of both. Subjects were followed for up to $1 \mathrm{y}$ after discharge from the ICU.

In the study by Bry et al, ${ }^{39} 30 \%$ of the subjects were current smokers and $41 \%$ had obstructive spirometry. A high proportion of the subjects had other non-respiratory pathologies, including hypertension (60\%), diabetes (38\%), and ischemic cardiomyopathy (19\%). Most subjects (62\%) were admitted with idiopathic acute respiratory failure. Mean $\mathrm{pH}$ at admission was 7.32 and mean $\mathrm{P}_{\mathrm{aCO}_{2}}$ was $61 \mathrm{~mm} \mathrm{Hg}$. Forty subjects received NIV as first-line therapy, while 4 were initially invasively ventilated and subsequently received NIV. The recorded NIV failure rate was $10 \%$, which compares favorably to the published literature, ${ }^{20,31,32}$ although mean BMI was lower in this study and respiratory failure was less severe.

After initial acute management in the ICU, 34 subjects received some form of PAP on discharge, and in half of those this was a new prescription. NIV was more frequently prescribed than CPAP, which was selected on the basis of positive overnight oximetry and when $\mathrm{P}_{\mathrm{aCO}_{2}}$ was $<45 \mathrm{~mm} \mathrm{Hg}$, and 9 subjects $(26 \%)$ required supplementary oxygen therapy. Eight subjects were considered to have no ongoing requirement for home ventilatory support. ${ }^{39}$

The authors found that subjects who required some form of PAP on discharge generally had a higher BMI than those who did not, and they required higher inspiratory PAP levels within the first $48 \mathrm{~h}$ of admission. There was no significant difference at admission in blood gas tensions, cause of respiratory failure, or prior use of home ventilatory support between those who were discharged with PAP and those who were not. Mean duration of NIV after discharge was $6 \pm 4.2$ months (no follow-up data were available for subjects discharged on CPAP). Adherence with NIV was surprisingly good, with mean adherence at 1 month being $5.7 \pm 2.9 \mathrm{~h}$ per day, and $7.1 \pm 2.1 \mathrm{~h}$ per day at 12 months. Poor adherence at 1 month was strongly associated with poor adherence at 6 months. Mean BMI was significantly lower at 12 months compared with baseline. Bicarbonate and $\mathrm{P}_{\mathrm{aCO}}$ levels were also significantly lower at 12 months when compared with baseline ( $26 \mathrm{vs} 27 \mathrm{mmol} / \mathrm{L}$ and $42 \pm 7$ vs $44 \pm 8 \mathrm{~mm} \mathrm{Hg}$, respectively, $P=.006$ and $P=.01$, respectively). There was a trend toward lower readmission rates in those individuals who received NIV at home (10\% readmission rate) compared with those who did not $(36 \%$ readmission rate, $P=.07)$.

So what have we learned from this study? Although this was a retrospective study, with all the limitations such a trial design entails, and the numbers included were small, which necessarily limits some of the conclusions that can be drawn, the study concurs with the findings of other, larger studies demonstrating that NIV is an effective strategy for the management of acute hypercapnic respiratory failure in subjects with obesity-hypoventilation syndrome, particularly in subjects presenting with an idiopathic decompensation of obesity-hypoventilation syndrome. ${ }^{31}$ 


\section{EDITORIALS}

Those subjects requiring domiciliary NIV or CPAP after admission had a higher BMI than those who did not, and they required higher inspiratory PAP levels at initiation of NIV. This matches with observational data confirming that the incidence of obesity-hypoventilation syndrome increases significantly as weight increases. ${ }^{3,5} \mathrm{~A}$ higher driving pressure is likely to be required to overcome the respiratory muscle load in more obese patients.

Finally, this study confirms findings from other studies that NIV in this group of subjects improves chronic respiratory failure ${ }^{34,36,37}$ and supports weight loss ${ }^{40}$ in adherent individuals. There was also a trend toward lower admission rates in those receiving domiciliary NIV, confirming data from longer-term observational studies. ${ }^{15,41}$

Despite the fact that obesity-hypoventilation syndrome is now a common indication for domiciliary NIV, significant questions remain. In particular, in relation to whether NIV is superior to CPAP with respect to longer-term outcomes such as cardiovascular events, length of hospitalization, and mortality, and whether either is superior to surgical and new non-surgical approaches to weight loss. It also remains to be demonstrated whether early initiation of NIV for nocturnal hypoventilation without daytime hypercapnia might be able to prevent progression to diurnal respiratory failure. Finally, the optimal NIV settings and modes for the management of respiratory failure in obesity-hypoventilation syndrome are not well established, and the role of newer modalities, including auto-titrating volume-targeted modes, is yet to be clarified.

\section{Alanna Hare MB MRCP MEd \\ Department of Ventilation and Sleep Royal Brompton Hospital London, United Kindom}

\section{REFERENCES}

1. Ng M, Fleming T, Robinson M, Thomson B, Graetz N, Margono C, et al. Global, regional, and national prevalence of overweight and obesity in children and adults during 1980-2013: A systematic analysis for the Global Burden of Disease Study 2013. Lancet 2014; 384(9945):766-781.

2. Akashiba T, Kawahara S, Kosaka N, Ito D, Saito O, Majima T, et al. Determinants of chronic hypercapnia in Japanese men with obstructive sleep apnea syndrome. Chest 2002;121(2):415-421.

3. Nowbar S, Burkart KM, Gonzales R, Fedorowicz A, Gozansky WS, Gaudio JC, et al. Obesity-associated hypoventilation in hospitalized patients: prevalence, effects, and outcome. Am J Med 2004;116(1): $1-7$.

4. Laaban J-P, Chailleux E. Daytime hypercapnia in adult patients with obstructive sleep apnea syndrome in france, before initiating nocturnal nasal continuous positive airway pressure therapy. Chest 2005; 127(3):710-715

5. Mokhlesi B. Obesity hypoventilation syndrome: a state-of-the-art review. Respir Care 55(10):1347-1362, 2010.
6. Garner DJ, Berlowitz DJ, Douglas J, Harkness N, Howard M, McArdle $\mathrm{N}$, et al. Home mechanical ventilation in Australia and New Zealand. Eur Respir J 2013;41(1):39-45.

7. Janssens JP, Derivaz S, Breitenstein E, De Muralt B, Fitting JW, Chevrolet JC, et al. Changing patterns in long-term noninvasive ventilation: a 7-year prospective study in the Geneva Lake Area. Chest 2003;123(1):67-79.

8. Mokhlesi B, Kryger MH, Grunstein RR. Assessment and management of patients with obesity hypoventilation syndrome. Proc Am Thorac Soc 2008;5(2):218-225.

9. Perez de Llano LA, Golpe R, Ortiz Piquer M, Veres Racamonde A, Vazquez Caruncho M, Caballero Muinelos O, et al. Short-term and long-term effects of nasal intermittent positive pressure ventilation in patients with obesity-hypoventilation syndrome. Chest 2005;128(2): 587-594.

10. Kessler R, Chaouat A, Schinkewitch P, Faller M, Casel S, Krieger J, et al. The obesity-hypoventilation syndrome revisited: a prospective study of 34 consecutive cases. Chest 2001;120(2):369-376.

11. Berger KI, Ayappa I, Chatr-Amontri B, Marfatia A, Sorkin IB, Rapoport DM, et al. Obesity hypoventilation syndrome as a spectrum of respiratory disturbances during sleep. Chest 2001;120(4):1231-1238.

12. Borel JC, Burel B, Tamisier R, Dias-Domingos S, Baguet JP, Levy $\mathrm{P}$, et al. Comorbidities and mortality in hypercapnic obese under domiciliary noninvasive ventilation. PLoS One 2013;8(1):e52006.

13. Castro-Añón O, Pérez de Llano LA, De la Fuente Sánchez S, Golpe R, Méndez Marote L, Castro-Castro J, et al. Obesity-hypoventilation syndrome: increased risk of death over sleep apnea syndrome. PLoS One 2015;10(2): 0117808 .

14. Priou P, Hamel J-F, Person C, Meslier N, Racineux J-L, Urban T, et al. Long-term outcome of noninvasive positive pressure ventilation for obesity hypoventilation syndrome. Chest 2010;138(1):84-90.

15. Berg G, Delaive K, Manfreda J, Walld R, Kryger MH. The use of health-care resources in obesity-hypoventilation syndrome. Chest 2001;120(2):377-383.

16. Hida W. Quality of life in obesity hypoventilation syndrome. Sleep Breath 2003;7(1):1-2.

17. Olson AL, Zwillich C. The obesity hypoventilation syndrome. Am J Med 2005;118:948-956.

18. Sugerman HJ, Fairman RP, Sood RK, Engle K, Wolfe L, Kellum JM. Long-term effects of gastric surgery for treating respiratory insufficiency of obesity. Am J Clin Nutr 1992;55(2 Suppl):597S601S.

19. Messika J, Ricard JD. Evaluation of risk factors for high flow nasal oxygen failure: a means to avoid disillusion. J Crit Care 2016;32: 222-223.

20. Duarte AG, Justino E, Bigler T, Grady J. Outcomes of morbidly obese patients requiring mechanical ventilation for acute respiratory failure. Crit Care Med 2007;35(3):732-737.

21. Shivaram U, Cash ME, Beal A. Nasal continuous positive airway pressure in decompensated hypercapnic respiratory failure as a complication of sleep apnea. Chest 1993;104(3):770-774.

22. González ÁO, Romero GP-B, Ormaechea IF, Flores RC, de Frutos NC, Mangado NG. [Evolution of patients with chronic obstructive pulmonary disease, obesity hypoventilation syndrome, or congestive heart failure undergoing noninvasive ventilation in a respiratory monitoring unit.] Arch Bronconeumol 2006;42(9):423-429.

23. Nava S, Hill N. Non-invasive ventilation in acute respiratory failure. Lancet 2009;374:250-259.

24. Ramírez-Molina VR, Gómez-de-Terreros FJ, Barca-Durán J, Masa JF. Non-invasive positive airway pressure in obesity hypoventilation syndrome and chronic obstructive pulmonary disease: present and future perspectives. COPD 2017;14:418-428. 


\section{EDITORIALS}

25. Kress JP, Pohlman AS, Alverdy J, Hall JB. The impact of morbid obesity on oxygen cost of breathing (VO(2RESP)) at rest. Am J Respir Crit Care Med 1999;160(3):883-886.

26. O’Donnell CP, Schaub CD, Haines AS, Berkowitz DE, Tankersley $\mathrm{CC}$, Schwartz AR, et al. Leptin prevents respiratory depression in obesity. Am J Respir Crit Care Med 1999;159(5 I):1477-1484.

27. Ip MS, Lam KS, Ho C, Tsang KW, Lam W. Serum leptin and vascular risk factors in obstructive sleep apnea. Chest 2000;118(3): 580-586.

28. Campo A, Frühbeck G, Zulueta JJ, Iriarte J, Seijo LM, Alcaide AB, et al. Hyperleptinaemia, respiratory drive and hypercapnic response in obese patients. Eur Respir J 2007;30(2):223-231.

29. Redolfi S, Corda L, La Piana G, Spandrio S, Prometti P, Tantucci C. Long-term non-invasive ventilation increases chemosensitivity and leptin in obesity-hypoventilation syndrome. Respir Med 2007;101(6): 1191-1195.

30. Piper AJ, Grunstein RR. Obesity hypoventilation syndrome: mechanisms and management. Am J Respir Crit Care Med 2011;183:292298.

31. Lemyze M, Taufour P, Duhamel A, Temime J, Nigeon O, Vangrunderbeeck N, et al. Determinants of noninvasive ventilation success or failure in morbidly obese patients in acute respiratory failure. PLoS One 2014;9(5):e97563.

32. Carrillo A, Ferrer M, Gonzalez-Diaz G, Lopez-Martinez A, Llamas $\mathrm{N}$, Alcazar M, et al. Noninvasive ventilation in acute hypercapnic respiratory failure caused by obesity hypoventilation syndrome and chronic obstructive pulmonary disease. Am J Respir Crit Care Med 2012;186(12):1279-1285.

33. Masa JF, Celli BR, Riesco JA, Hernandez M, Sanchez De Cos J, Disdier C, et al. The obesity hypoventilation syndrome can be treated with noninvasive mechanical ventilation. Chest 2001;119(4):11021107.
34. Masa JF, Corral J, Alonso ML, Ordax E, Troncoso MF, Gonzalez M, et al. Efficacy of different treatment alternatives for obesity hypoventilation syndrome: Pickwick study. Am J Respir Crit Care Med 2015;192(1):86-95.

35. Borel J-C, Tamisier R, Gonzalez-Bermejo J, Baguet J-P, Monneret $\mathrm{D}$, Arnol N, et al. Noninvasive ventilation in mild obesity hypoventilation syndrome: a randomized controlled trial. Chest 2012;141(3): 692-702.

36. Piper AJ, Wang D, Yee BJ, Barnes DJ, Grunstein RR. Randomised trial of CPAP vs bilevel support in the treatment of obesity hypoventilation syndrome without severe nocturnal desaturation. Thorax 2008; 63(5):395-401.

37. Howard ME, Piper AJ, Stevens B, Holland AE, Yee BJ, Dabscheck $\mathrm{E}$, et al. A randomised controlled trial of CPAP versus non-invasive ventilation for initial treatment of obesity hypoventilation syndrome. Thorax 2017;72(5):437-444.

38. De Miguel Díez J, De Lucas Ramos P, Pérez Parra JJ, Buendía García MJ, Cubillo Marcos JM, González-Moro JMR. [Analysis of withdrawal from noninvasive mechanical ventilation in patients with obesity-hypoventilation syndrome. Medium term results] Arch Bronconeumol 2003;39(7):292-297.

39. Bry C, Jaffré S, Guyomarc'h B, Corne F, Chollet S, Magnan A, Blanc FX. Noninvasive ventilation in obese subjects after acute respiratory failure. Respir Care 2018;1:28-35.

40. Murphy PB, Davidson C, Hind MD, Simonds A, Williams AJ, Hopkinson NS, et al. Volume targeted versus pressure support non-invasive ventilation in patients with super obesity and chronic respiratory failure: a randomised controlled trial. Thorax 2012; 67(8):727-734.

41. Windisch W. Impact of home mechanical ventilation on health-related quality of life. Eur Respir J 2008;32(5):1328-1336. 